going to bed, and that as a rule the patients are much better and brighter during the evening. A point of some interest is that more fits occur in the house than outside in the garden or fields, and this apart from greater difficulty in registering the number outside; while there seems to be a :general impression that more fits occur during warm and close weather than during the cold.

2. Severity of the fits.-Here, again, there is a majority in which an amelioration in the severity of the attacks occurs, while in a minority no material alteration is noticed, and in some a decided tendency towards increase in severity. Upon this point, however, it is more difficult to obtain accurate observations. In some of the colonists severe fits gave place to attacks of petit mal; in others, attacks of an average nature became more severe.

3. General mental state. - In quite a minority there has been a progressive tendency towards dementia. In some it appeared to be the natural course of the disease. In others it was owing to the frequency and severity of the fits, or of both combined. In the greater number no such mental deterioration has been observed. On the whole, the mental state of the colonists, considering the duration of the disease, is good. Some of them are capable of work requiring individual alertness and tact, while most are able to do good work under supervision. But the greatest benefit which this system of treatment is capable of producing lies in the general moral effect which it has upon the individuals. These persons amongst the poorer classes are in many instances regarded as "family lepers," the outcasts of the community, between whom and their relatives there is little sympathy. In a colony each epileptic is readily brought to see that he is as useful a person as his more highly favoured brotber if placed under proper conditions. Here interest is taken in his work, in his mode of life, and in his amusements, with the natural result that he takes greater interest in himself and obtains a feeling of higher selfi-respect.

4. General pliysical state.-It is under this heading that the greatest improvement has been noticed. Without exception the general health of each colonist has materially improved. They all put on weight, and this, notwithstanding the fact that they may be subject to frequent and even severe fits.

But it may be asked. What kind of work has been found most conducive to good health among the epileptics? It may oe stated that all forms of work appertaining to the fields or the garden have been found beneficial, while good work is also done in the carpenter's shop by picked men. The farm of 135 acres is worked by the colonists with the addition of a few farm labourers and overseers (bailiff and gardener). In the summer months matches are arranged between the cricket club of the colony and the various local clubs of the district, but football is not allowed. Contrary to the experience of the authorities of the Craig Colony for Epileptics, it has been found that the granting of bolidays to the colonists at intervals is of value. Certain important precautions are taken before leave is given, but on the whole such a change has been of material service to the individual. It is scarcely necessary to state that the colonists have been carefully selected by the medical committee from a large number of applicants. The points to which attention is especially directed are: Has the epileptic been unable to obtain employment? or has he been discharged from one or more situations by reason of the fits? Is he capable of work ander direction? and a point of great importance lies in a statement upon the absolute freedom of individuals from attacks of violence, mania, or other symptoms indicating insanity.

By way of conclusion, a summary of the evidence collected by the Charity Organisation Society from the results of this method of treating epileptics in the colonies on the Continent may be quoted 10: "Any attempt to provide for the treatment of epilepsy, if large numbers have to be considered, should combine school-teaching with medical treatment and supervision. For young persons and adults regular but not too laborious employment is necessary. For all alike, for the furtherance of self-control, and for healthy enjoyment a well-ordered home life is reciuired, and these the colony system provides. Medically, if the serious nature of the -disease be taken into account, the colony system produces the best results. For the worst cases, and to provide against the constant ailments of many of the colonists, hospital

10 Report on the Epileptic and Crippled, 1893. accommodation is necessary. This system will have to furnish accommodation suitable for patients of all classes, the highest who may wish to have the best fare and rooms, and the lowest. The growth of the colony system is remarkable. It meets a very widely-felt need. This need is not met in England, for it cannot be said that to provide a residence in a workhouse is sufficient, and that is all that is now done."

I have endeavoured to show in this article that the need has now been met in this country, and that this form of treatment is being successfully carried out at the epileptic Colony, Chalfont, Bucks.

Queen Anne-street, $W$.

\section{ON THE DIAGNOSIS OF CERTAIN SO- CALLED RHEUMATIC DISEASES FROM EACH OTHER AND FROM RHEUMATISM.}

By GEORGE PARKER, M.A., M.D. CAN'TAB., ASSTSTANT PHYSICLAN, BRISTOL GENERAL HOSPITAL.

THE distinction between the group of affections due to rheumatism and those of different origin is a much discussed and difficult subject. The limits of this group have of late been extended in some directions and diminished in others, Reasons have been given for including in it the most unlike diseases, such as chorea and erythema nodosum, while others which were formerly insluted as typical in stances have been removed and shown to be due to recognised microbial infections or pyæmia. This has been especially the case with most forms of scarlatinal rheumatism, of malignant endocarditis, and gonorrhoeal arthritis. Many uterine and ophthalmic affections have been also excluded. On the one hand, arthritic symptoms have been largely discredited as a test; and, on the other hand, the type of the disease as seen in children does not seem more trustworthy, since, for example, endocarditis has been of late shown to arise from the poison of such different complaints as phthisis, gonorrhœa, and even typhoid fever. The fact is, as Dr. S. Mackenzie remarks, we have no single criterion of rheumatism. We are ignorant of its causes, whether it is at first a local disease, and if so where it arises in the body. We have only a bundle of symptoms, almost any one or any group of which may be present in other complaints. It is of little use to say that various causes produce identical symptoms when they affect the same organ, such as a joint. If there is no test for rheumatism we shall want to know whether the other causes producing similar symptoms have any distinguishing marks. It seems the most promising line of inquiry, then, to focus clearly our ideas of those affections which mimic rheumatism and produce like phenomena. Some of them may be capable of exact definition, and we may then by a process of exclusion arrive at $a$ true conception of rheumatism itself. This, indeed, has been the most fruitful method in the past. Leaving on one side for the present chorea and some other children of doubtful paternity, there are a large number of skin, joint, and pyæmic affections to be considered, such as Osler's erythema exudativum, Quincke's œdema, Henoch's purpura, erythema nodosum, gonorrhœal, scarlatinal, diphtheritic, influenzal, and other forms of pyæmic arthritis, purpura hæmorrhagica, and hæmophilia. Every symptom of rheumatism is seen in one or other of these, but many of them have a distinct individuality and sequelæ which will enable us to withdraw certain cases of seeming rheumatism and refer them to their true parentage. As I happen to have met with several instances of these disorders of late I shall briefly refer to the chief types, with abstracts of my cases, and mention any points which are against a rhenmatic origin. To return for a moment to the general question of diagnosis, it may be said that we should be largely guided by a history of previous rheumatic attacks ; but this is undoubtedly very misleading and the source of much error, for such histories often refer to a previous attack of something else which bore a superficial resemblance to that disease. Especially is this true since some of the allied affections tend to recur again and again. Even endocarditis is no evidence of rheumatism, for, as we have said, it is produced by numerous causes. There is, indeed, no reason why one of 
these attections should not occur in a person subject to rheumatism, so that even if the previous attack was really of that kind we must decide the case upon its merits. Of course, if rheumatism is really found far more frequent]y in connexion with one of these affections than in healthy persons we can argue a special relation, but its incidence on the general population is not accurately known.

The action of salicylates, too, is an uncertain guide. Their failure in an apparently typical case of acute rheumatism may lead us to consider carefully our diagnosis, but their reducing the pyrexia is no proof of rheumatism. A French writer has recently denied any specific action to them and considers that they merely exert a sedative or paralysing effect on all inflamed protoplasm. Whether this is so or not their action is not entirely confined to rheumatism. Thus we might be easily misled by them in cases of infuencal arthritis such as bave been of late described by Dr. Sansom. ${ }^{1}$ It is true that salicylates will often relieve the pyrexia and pains of influenza; but these cases where troublesome joint mischief accompanied and followed an attack showed from their course and sequelæ that they were certainly not rheumatic. In some of them the affection proved to be rheumatoid arthritis, which is a very different thing Others developed into various forms of neuritis. In all there was little or no effusion within the joints, but the $\in$ nds of the bones were tender and enlarged and the seat of most of the pain. In no instance has Dr. Sansom traced valvular heart disease to an attack of influenza, though dilatation, cardiac neuritis, and angina are not uncommon. Still, these cases were at first very like ordinary rheumatism. It is interesting to notice that some observers claim that salicylates will often relieve the crises of tabes, and of this I have seen some apparent instances, yet no one regards the arthritic symptoms of that disorder as rheumatic.

Henoch's purpura as originally observed by him in children was of a very definite type, presenting severe abdominal pain, intestinal and renal bæmorrhages, purpuric eruptions, often with romiting, swelling of the joints, œdema of the hands and feat, and nephritis. Ton Dusch and Hoche, and recently Osler, have collected some sixty cases, both in adults and children. If we refer to Osler's account ${ }^{2}$ we find that he describes it as an ery thema exudativum multiforme ; but he notices that the skin affections may be absent altogether or appear only in one of the recurrent attacks which may present themselves year after year. The most constant symptom is a sort of gastric crisis, which may vary from a stomach-ache to an unbearable agony. With this there commonly comes on vomiting and diarrhœa, as well as pain and swelling rather around than in the joints. There is not unfrequently pyrexia, sometimes delirium, and nephritis of various degrees, from slight albuminuria to a fatal form with casts and anasarca. Hæmorrhages from the kidneys, bowels, and stomach are frequently seen, and recurrent attacks of bronchitis and hæmoptysis may occur, as well as eruptions of purpura, erythema, and urticaria occasionally we meet with affections of the heart and spleen Both here and in a very different disease-purpura hæmorrhagica-the melæna may arise from a slough and subsequent ulceration of the intestines, which causes, not only bleeding, but intractable diarrhcea and even perforation. The following is the history of a well-marked case under my own care for a time.

CASE 1. - A young seaman in perfect health was attacked on July 26th, 1896 , by severe abdominal pain, for which he took castor oil. A little urticaria appeared and vanished as quickly. On the 28th the pain became intense, and he was found lying helpless and prostrate, with some tenderness to the right of the umbilicus, but the attack, though puzzling, was clearly not one of abdominal obstruction or appendicitis. The heart, the temperature, and the lungs were normal, nor was there any affection of the skin, kidneys, or joints. Some relief from the distress was obtained by the use of opiates, till on the 31st much pain and swelling of the wrists, especially of the right one, occurred. The temperature was still normal, but on Aug. 1st it rose to $100^{\circ} \mathrm{F}$., and the pains became worse, with much aching in the thighs. Salicylates had little effect. An ulcer appeared on the edge of the tongue, as though a piece had been bitten out. On the 8th, and for a week onwards, the temperature varied from $100^{\circ}$ to $102^{\circ}$, but meanwhile the arthritis disappeared and the appetite became good. After sharp increase of the gastric pain, with vomiting and diarrhcea, on the 13th, these symptoms declined, but some dulness and diminished respiratory murmur were noted over the left scapula. On the 20th an extremely painful cdematous swelling spread over the right side of the scalp and forehead, and closed the right eye. There was no redness, and the pain was sufficiently severe to interfere with sleep, but the temperature meanwhile fell to normal and the appetite became voracious. In four or five days the swelling subsided, but on the 26th a purpuric rash appeared on the legs of a dull pale red, forming numerous close-set spots of the size of sixpence, extending a short distance up the thighs and accompanied with slight odema. From this time gradual improvement set in, the patient gained flesh again, his anæmic condition gradually disappeared, and he returned to work on Sept. 11th sound and well in every respect.

On at least one occasion during the illness the romit was blood-stained, and the apparent absence of any evidence of intestinal bæmorrhage may have been due to oversight in the nursing. It is noticeable that no history of poisonous food, pork, or shell-fish or of previous rheumatism was obtainable I can see notbing in the general aspect of such cases when fully developed to entitle us to call them rheumatic. Dr. S. Mackenzie regards Osler's own group of eleven instances as a distinct form " where the hæmorrhages are accidental, not essential," but he appears to refer them all to the rheumatic class. Now it seems to me that there is a strong argument against this in the prevalence of nephritis, which occurred in fourteen out of the sixty-one cases reported; and in the rarity of endocarditis, which was present in only two out of sixty-one, and those not mild ones, for no less than thirteen were fatal. The occasional splenic enlargement is another point in the same direction. It appears rather that we have here a definite disease of ar an acute toxæmic type, which I will call the Osler-Henoch, and which may be simple or bæmorrhagic. Many supposed cases of rheumatism are probably of this nature, which it is important to distinguish, if only from the difference in the sequelæ to be expected. It seems difficult, on the other hand, to look on this disease as erythema multiforme or purpura hæmorrhagica, since the eruptions may occur only once in four or five attacks, at any rate in adults. Dr. G. A. Sutherland, ${ }^{3}$ in reporting recently three cases, looks on the joint symptoms as septic, though nothing has been discovered bacteriologically. Foreign opinion at the late Dermatological Congress was against any connexion with rheumatism.

Angio.neurotic adema is a name given to another group of cases which are related in several ways to the Osler-Henoch disease. They are sometimes spoken of as Quincke's cedema, and the attacks are often ushered in by severe gastrointestinal pain and disturbance. In one variety large patches of cedema of irregular shape appear on various parts of the body.

CASE 2.-A patient of mine, a widow aged fifty-two years, has suffered from it for several years. The wheals or patches recur frequentiy on the left cheek, the lower lip, and on the eyelids, where they seem almost fluid and transparent. There is no pain, redness, or itching, but a little pricking when the patches begin to swell up, which takes place every few days. She enjoys otherwise good health, but gives a history of "rheumatic fever," which may or may not be correct; there is no cardiac murmur. Two or more fingers in each hand are affected by lesions which appear to be those of rheumatoid arthritis and grate on moving. On the right olecranon and on the left wrist are subcutaneous nodules. The latter, again, it should be noted, are not found in rheu. matism alone. Jamieson speaks of the frequently observed connexion of this cdema with rheumatoid arthritis, but beyond this nothing is known of its pathology. No relation whatever to true rheumatism bas bef $n$ made out. though fugitive cdemas, apart from the arthritis, do sometimes appear in the latter.

In rheumatoid arthritis we see another well-defined disease distinct from rheumatism, yet presenting many of its ordinary symptoms. Bannatyne and his fellow workers have apparently shown that in this complaint we have a toxæmic infection by a bacillus with irregular pyrexia, sweating, and tachycardia, and not infrequently pigmentation of the skin and purpura. Hæmorrhage from the mucous membranes is very rare, with the exception perhaps of hæmatemesis. The joint affections and muscular atrophy are the most commonly 
noticed symptoms, and it is remarkable that the great majority of the sufferers are women. This predilection for the female sex is shown, curiously enough, in the cases of erythema multiforme and purpura which Dr. Stephen Mackenzie collected as showing the so-called rheumatic history, the proportion being four or five to one. Another point of similarity with these diseases and Quincke's cedema is the occurrence of gastric crises which may be severe and periodical. Well-marked instances have been recorded by Dr. H. Waldo, and a typical patient of my own, thirty-two years of age, unmarried, complains of them strongly, as well as of the ordinary joint troubles. The history of the patients, the joints affected, the deformities, the sequelæ, and the results of treatment are other well-known points wherein this disease differs from rheumatism, though it bears a superficial resemblance.

I must onJy refer briefly to certain forms of septic arthritis, many of which are clearly non-rheumatic. Such are those seen in gonorrhoea, scarlet fever, diphtheria, especially that following the use of antitoxin, variola, and erysipelas. We may at once dismiss the purulent effusions. Gonorrbœal arthritis is intractable, tends to develop adhesions, and affects special joints, such as the temporo-maxillary, and is sometimes accompanied by purpura and endocarditis where the gonococcus has been isolated. Serous scarlatinal arthritis has usually been accepted as rheumatic. Here again fuller knowledge has narrowed the field. Dr. R. W. Marsden ${ }^{*}$ points out that the affection is either $(a)$ a simple synovitis which occurs about the sixth day and is six times more common than all the rest put together, $(b)$ septic, $(c)$ tuberculous, or $(d)$ true rheumatism. The last only occurs during a late stage of convalescence, and is always subacute. The early type with which it is usually confounded never recurs, is not accompanied by sweating, does not fly from joint to joint, rarely if ever affects the heart or shows any other rheumatic sequelæ, and is specially apt to develop in the tendons on the back of the hand rather than in the wrist.joint. The true rheumatic type is rarer even than the purulent forms, and appears in a quite insignificant proporGion of cases.

Infective endocarditis may present joint affections, sweats, and purpuric rashes, and was formerly regarded as rheumatic in origin. In fact, the transition in the symptoms from septic cases to ordinary rheumatic endocarditis is marked by insensible gradations. Still, it is recognised that most malignant cases are produced by strepto-, diplo-, or staphylococci, though the presence of the lesions of former rheumatic endocarditis favours the outbreak of the disease. Very rarely, says Dreschfeld, it may complicate or follow acute nheumatism. It is usually, if not always, a septicæmia. The symptoms at first may resemble in some degree those of Henoch's purpura, as in a case of my own, where a somewhat purpuric patch went on to gangrene of the finger where it occurred; but the peculiar sweats and pyrexia, the heart signs, and the emaciation are soon distinctive.

Hcemophilia is, indeed, a permanent and hereditary condition, due possibly, as Wright suggests, to a deficient formation of polynuclear corpuscles; but we often meet with attacks in those suffering from it which resemble rheumatism. There is suddenly felt a discomfort and sensation of tension in various parts of the body, the joints swell and become painful, so that the epithet "rheumatic" has been applied to them even by Bristowe. Purpuric spots and hæmorrhages follow, though no wound has been received, and of course hæmatemesis and melæna may occur. Yet this apparent arthritis is probably due merely to hæmorrhage in or around the joints; the throbbing will be felt around any wound far away from a joint before renewed bleeding, as I saw lately in a patient under the care of $\mathrm{Mr}$. Fendick, and the purpuric rash is also produced by any slight blow. Other symptoms of rheumatism are wanting and the disease is limited to the male sex.

The still rarer affection called pulmonary osteo-arthropathy weems to have no connexion whatever with rheumatism, though the joint affections may be easily mistaken for it.

To turn to erythema multiforme. We have seen little reason for looking on the Osler-Henoch type as rheumatic, but this has been asserted with respect to the other forms. Kaposi notices the joint pains, occasional pyrexia, endocarditis, and meningitis sometimes seen in them, as in other septic affections; while Coulard and Garrod show that a rheumatic history is very common indeed. Erythema nodosum especially is claimed as certainly rbenmatic, chiefly on the ground of the great number of patients who have such a history, and partly because the two affections occur together not infrequently. Thus Mackenzie found this conjunction in seventeen cases out of 108 collected from various hospital records, besides twelve others in which the erythema followed rheumatism. The symptoms most relied upon were arthritis, sweats, and sore-throat, while endocarditis developed in some patients at the time of the attack. Even the value of this strong evidence depends on the strict analysis of the cases. As I have said before, joint pains and endocarditis are not uncommon in many septic diseases, and may have been taken for true rheumatism by the compilers of these records if they chanced to be less careful and accurate observers than Mackenzie himself. It is a curious fact that erythema nodosum, which the English and Vienna schools distinguish so carefully from erythema of other kinds, is often accompanied by them and by purpura, the various rashes being visible on various parts of the body at once. The causation of the various ery themas is not easy to reconcile with theories of rheumatism. They of ten follow the ingestion of noxious food and occur in epidemics in spring and autumn. Both the other varieties and erythema nodosum are most common in women (nodosum being particularly rare in males) during early life or when suffering from some uterine disturbance. The meningitis, gastric troubles, and renal bæmorrbages occasionally seen in them are unknown in pure rheumatism. In any case, as the Dermatological Journal remarks, there are on Dr. Mackenzie's own figures 50 per cent. which show no rheumatic symptoms or histories whatever. If erythema nodosum has any connexion of the kind it is probably only that one disease favours the invasion of the other, and not that erythema nodosum is rheumatism attacking the skin.

In purpura hemorrhagica there is another toxæmic infection of definite character, though the skin and other symptoms are occasionally almost indistinguishable from purpuras occurring in rheumatism. The following was a severe case which I attended recently.

CAS 1 3. - A young man developed a slight purpuric rash at Easter last. He remained at home for a few days and then returned to work, though the eruption continued to appear for some weeks. He felt perfectly well, but the rash at last began to increase, and besides the petechiæ dark-coloured blebs were now seen, which were especially noticeable on and under the tongue and upon the soft palate; a little bæmorrhage from the gums followed. He then presented himself at the Bristol General Hospital as an out-patient, and was with difficulty induced to come into the house, where the next day he died from a hæmorrhage in the brain.

In such cases we often find every evidence of septic intoxication, fever, sweating, joint pains, and a comatose state. Moreover, there is some evidence as to the agent causing the condition. Tizzoni, Babes, Kolb, and Letzerich have all found bacilli present in the tissues and blood of patients which reproduced it in a modified form in animals, and Letzerich managed to infect himself from his pipe during his researches on the subject, and suffered a pretty severe attack. Watson Cheyne also found colonies of bacteria inside the vessels in two cases, though he failed in others. Quite recently Hayem and Rendu showed that the clot formed trom the blood in this disease does not contract and squeeze out serum as it does with normal blood, or, indeed, as the clot does also in the secondary non-bæmorrhagic purpuras, which I shall speak of below. Besides the gastric and other hæmorrhages and occasional persistent diarrhoea from ulceration of the intestines, large areas of the skin may be rendered gangrenous by the hæmorrhages. Now, definite as the disease is, several cases where these severe bleedings occurred have of late been claimed as rheumatic Thus, we find one reported by Surgeon-Captain Fayrer, where the tongue and part of the penis were destroyed by gangrene, though the patient, a healthy soldier, regained his health; but it is surely more rational to regard the symptoms as ordinary effects of the purpuric toxin instead of exceptiunal ones of the unknown rheumatic poison. Eren if the attack concurs with one of acute rheumatism, as in a rare instance related by Dr. S. Mackenzie, we know that such coincidences are met with in other diseases; that pure phthisis is exceptional ; that rheumatism itself chooses injured joints, and bacteria when injected into the tissues show the same predilection; while the typhuid bacillus so intensifies the bacillus coli that the latter produces a large part of the intestinal 
lesions. Similarly, these two diseases do at times coexist, and possibly one favours the growth of the other. In the great majority of severe attacks of rheumatism, however, there is no indication of anything of the kind, and the purpuric complication is at best a rare one. The simple forms of purpura which do not affect the mucous membranes or produce hæmorrhages are produced under various conditions. We find them caused by drugs such as iodide of potassium, and again in cancer, heart disease, and leukæmia. I am not concerned to deny the occurrence of this symptom in rheumatism any more than its appearance with arthritis after the injection of antitoxin, or during a streptococcal pyæmia. As Dr. S. Mackenzie describes it, during ordinary rheumatism, or before an attack or after, the patient may complain of a dull pain or feeling of tension in the legs. Towards evening or during the next day small red spots appear symmetrically on both legs and soon take a purple tinge, while the discomfort passes away. Successive crops follow and may even spread to the arms, but any hremorrhage is extremely rare. Oat of forty-two of his cases rheumatism was present, or had occurred in thirty-five, and pyrexia was found in a third of them. I do not know of any evidence to show whether this form is really the effect of rheumatism or of a secordary infection, but some authorities who accept a rheumatic purpura make peliosis a distinct disease, and include under it a large proportion of such cases. They define it as marked by arthritis and a rash appearing around the joints, papular at first, and then hæmorrhagic, sometimes followed by intestinal ulceration and diarrbeea. It is, they say, unaffected by salicylates and rarely causes endocarditis. Dr. Mackenzie found albuminuria and abdominal pain in about a tenth of his cases, which is rare in rheumatism, though not unknown, especially where endocarditis has occurred. Thus it is probable that many of these instances are really purpura hæmorrbagica, or the Osler-Henoch disease, though symptomatic purpura may be found in rheumatism as a result of blood changes.

To sum up, we find that a large number of diseases formerly included under rheumatism have been gradually differentiated from it. First this was done with respect to gout, then many septic joint disorders were separated from it, and now the diseases in the group under consideration are shown to have definite characters, histories of their own, and to be followed by lesions, such as nephritis and neuritis, unknown in rheumatism. This enables us to place under them also many ill-defined cases usually regarded as rheumatic from the joint and heart symptoms present, for close observation shows in them symptoms quite different from those of rheumatism, though common in the diseases referred to. Lastly, these affections do sometimes coexist with rheamatism and produce their own symptoms, and, indeed, they possibly favour the evolution of rheumatic outbreaks, and are themselves aided by its presence.

Clifton.

\section{CLINICAL TYPES OF PNEUMONIA. ${ }^{1}$}

\section{By W. J. TYSON, M.D.DURH., M.R.C.P.LOND., F.R.C.S. ENG.}

SENIOR MEDICAL OFEICER, VICTORIA HOSPITAL, FOLKESTONE.

I HARDLY know of anything more interesting in one's spare hours than to read a book on general medicine or surgery written fifty years or so ago. What an immense change has come about in almost every department of our profession whether the etiology or treatment of disease be considered! I well remember some twenty years ago, whilst dressing for the late $\mathrm{Mr}$. Cooper-Forster, seeing a woman who was dying from acute septicæmia after an amputation of the breast had been performed, Mr. Cooper-Forster then remarking that it was impossible to account for these deaths, and that every now and then such a result would follow from an operation as the above. Even in my own recollection one most important disease has almost disappearedviz., ague - and another-i.e., lardaceous disease is becoming very rare; the former forty years ago was rife in my own neighbourhood, and the latter was common when I was a student.

I A paper read at Rochester on March 19th, 1897, before the members of the North, West, and East Kent Districts of the South-Eastern Branch of the British Medical Association.
Before coming to the subject of $\mathrm{my}$ paper-the various types of pneumonia that are met with clinically-I will consider the past history of pneumonia. There can be little doubt that what is called to-day croupous, or lobar, pneumonia was the only form of the disease known to our forefathers. Watson, writing in 1848, in the third edition of his "Practice of Medicine" practically only describes lobar pneumonia; he gives a few lines to catarrhal or lobular pneumonia, but omits all reference to its pathology, physical signs, and treatment. Fibroid pneumonia he does not mention. Watson at the above date pictures most graphically all the classical signs and symptoms we now generally associate with an acute attack of sthenic pneumonia occurring for the most part in a young person from the so-called cause of chill, such as fine crepitation followed by bronchial breathing, bronchophony, dulness on percussion, the characteristic sputum, the relativeincrease of the respirations as compared with the pulserate, \&c. ; but, strange to say, the "crisis" is not referred to at all, probably, I suppose, because the thermometer was not in use at this date-still one would have thought that the application of the hand and the often collapsed state of the patient at this critical time would have demanded some special notice to this point. It was in this form of the disease that one, or sometimes all, of three well-known socalled specifics were used-viz., bleeding, tartar emetic, and' calomel. The confidence in the foregoing was unbounded, and it would have been almost impossible for anyone not to have. employed them, such was the faith in their efficacy. Graves, writing in his "Clinical Medicine" some few years before the period I have just referred to, speaks only of croupons. pneumonia. He mentions as a rather common sequela or complication of the disease abscess of the lung; but on carefully reading over the notes of the cases there is some doubt. in my mind whether these were not for the most part local empyemata or tuberculous cavities. However, at this date no exploratory needling or incision was made. Graves also. recommends the old treatment of bleeding, tartar emetic, and calomel, but he advocated, as a rule, only two bleedings of: twelve ounces at each time. T'he treatment by digitalis and strychnia is not mentioned at this date. My own reading and experience lead me to think that ordinary sthenic croupons pneumonia is not met with so commonly to day as it was some years ago. I rarely see in hospital or private practice the disease accompanied with all the well knownI was going to say the examination or text-book-signs and symptoms. I believe that the type has somewhat changed. The various clinical varieties that are present with us now are in some instances due to different causes and: require different treatment.

The phrase "congestion of the lungs," too, is constantly employed by the public and not infrequently by the members. of the profession. It is quite difficult to understand in what sense it is used by the latter; when used by the former I pay noattention to it. Many years ago Dr. S. Wilks was constantly objecting to the prevalent use of the word "congestion," and he taught, I believe, that the term should only be used when the first stage of pneumonia was indicated. There. can be no doubt that the first stage of a croupous pneumonia is that of congestion; but the question before us is, Is there. such a thing as a congestion of the lung, pure and simple, apart from its association with pneumonia, and one that is not passive in origin, as seen in heart disease? I think that such a condition-which may be called "simple congestion" at present for want of a better term-does exist. It is almost. impossible to demonstrate it as it is not a cause of death. The following case came under my notice a few weeks ago. A man. middle aged, was admitted into the Victoria Hos pital, Folkestone. At the base of the left side there was dulness on percussion, with bronchial breathing and bronchophony. On the right side at the base there was some loss of tone on percussion, with fine crepitation, but no bronchial breathing and no bronchophony. At the post-mortem examination the base of the left lung was found to be in a state of red hepatisation, with the characteristic appearance and qualities, and the base of the right lung in the condition known as congestion or engorgement. Now most of us have met with cases which gave only the signs that go with a congestion, and the subsequent history of the case has led us to make no further diagnosis. I see no reason, judging from analogous states in other organs and parts of the body, to say that this congestive state of the: lung must necessarily go with pneumonia. On the other hand, I think the public and many of the profession use the word far too frequently and far too loosely. 